particular excellence in the method of language-teachers. I refer to the practice of making the students acquainted with the works of great writers at the earliest possible period. I should like to see fairly advanced classes of chemical and other students, in schools and elsewhere, reading, with assistance, some of the more suitable memoirs of such men as Davy, Graham, and Faraday. I do not advocate the complete abandonment of text-books, but I should rejoice greatly if their use could be considerably restricted and something better substituted. Has not this neglect of the original writings of great workers by our teachers something to do with the subsequent neglect of research by so many of their pupils? There is of course this practical difficulty in the way of what I propose- that original memoirs are not at present obtainable in a form in which they can be put in the hands of whole classes of students. If my suggestion should prove acceptable to even a few teachers however, that is a difficulty which could be very easily surmounted.

(5) When any one proposes to himself a change in his mode of teaching, unless his position is quite exceptional, he always finds himself confronted by one solid difficulty, viz. public examinations of one kind or another. Teachers at first inspired the examiners. Now they find themselves too often helpless before them. In the face of our various examining Boards individuals are nearly powerless. The time seems to have come when an association of science-teachers for the improvement of science-teaching is a real necessity-something more or less resembling the Association for the Improvement of Geometrical Teaching. Such a body would often be invaluable. It could, by the appointment of committees, and perhaps by pecuniary help, promote such experiments as I have suggested in Paragraph (4). In cases such as the recent unfortunate action of the War Office, it might be expected to do good work by replacing individual by organised action. And it could hardly fail, by bringing teachers and examiners into contact, to do much to make advances in teaching more possible than at present.

My various remarks on so many points have necessarily been brief and incomplete. I could not, in the form of a letter, go fully into questions of advantage, disadvantage, and difficulty. I shall have amply attained the object I have had in view if I have helped to draw attention to these important matters.

W. A. Shenstone

\section{Do Flying-Fish Fly or Not?}

I HAVE crossed the Atlantic and Indian Oceans many times and at different seasons of the year, but until my last voyage to Calcutta I was unable to answer this question positively. For days together, aided at times by a powerful field-glass, I have endeavoured to establish satisfactorily whether these nimble little fish used their membranous wings after rising above the surface of the sea or not. An old and valued friend, the late Charles Kingsley, on his voyage to the West Indies, so graphically painted in the pages of "At Last," records his opinion in favour of the wings being employed as a means of propulsion through the air after the fish quit their more natural element, and I certainly inclined to the same belief, although, owing to the "ever-vexed" condition of the Atlantic, I found accurate observation impossible. In the Indian seas the fish appear at rarer intervals, and limit correspondingly the chances of watching their movements.

On a blazing afternoon in May last, on board the steamer Indin, some hundred miles off the African coast on the way to Ceylon, I had the first and only opportunity I ever enjoyed of establishing beyond dispute this vexed question, which I am not aware has hitherto been settled. The sea was perfectly calm, covered here and there with a yellow scum which exhaled a fresh unpleasant smell like a beach covered with sea-weed at low water. From the spar-deck above the cabins, which were fitted up in the fore-part of the ship, I could descry at frequent intervals shoals of flying-fish rising and apparently fluttering from 50 to 100 yards before dipping again into the mirror-like surface of the ocean. Along with several of the passengerssome of them provided with field-glasses-I vainly endeavoured to make certain whether the fish did or did not make use of their wings after leaving the water. Opinions were divided, for, owing to the rapid motion of the fish, it was impossible to keep any one of them long enough in the field of vision. It occurred to some of us at length to look over the bows of the steamer, and there we saw a sight not soon to be forgotten. The flying-fish appeared frequently shooting upwards in large numbers from the blue glassy depths directly beneath us, as the shoals were disturbed by the vessel's cutwater, and their every movement plainly discernible while under water and from the moment they rose "winnowing the waving element" with expanded wings ard tail, bent on escaping the pursuing craft, until they dipped again into the sea for shelter or to obtain fresh impetus for continued flight. I satisfied myself, and so did my fellow-watchers, that after a certain number of strokes with wings and tail-from twenty to thirty, varying with the dimensions of the fish-which we repeatedly counted, as they left corresponding impressions on the oily surface of the water, these appendages were not employed to accelerate, but merely to sustain, the flight while the fish remained in the air. The curved impressions left by the wings on the water appeared, as nearly as I could judge, from twelve to eighteen inches apart on either side of the fishes' course until clear of the water. The tail left no perceptible imprint, but could be clearly seen waving from side to side, adding doubtless considerably to the impulse. After rising out of the water the wings and tail remained ridged, but in some instances were slightly twisted to preserve the equilibrium. Occasionally a fish appeared to lose its balance in the hurry of escape, and toppled over in a ridiculous fashion.

The yellow scum also attracted attention, tinging the ripple at the bows a deep orange. I had some of it brought on board, and a fellow-passenger of an entomological turn placed some under a powerful microscope, but failed to determine the species to which it belonged. Ten years ago, near the same place, I observed the water assume a dirty yellow tinge, as though it had suddenly shoaled, while the same unpleasant smell was perceptible. The discoloration and smell I found to be due to the presence of vast quantities of animalcula, about a quarter of an inch long, semi-transparent, jointed like a cane, and about the thickness of a small needle.

8, Garden Reach, Calcutta

\section{Earthquake Measurements}

I REGRET that Prof. Ewing should take so much to heart my criticisms of his results of earthquake registration. I think that if we can get a single movement instead of a double one we gain much by halving the errors of double registration, extra friction, complexity of calculation, \&c., all causes that tend to increase the imperfection of the results.

Neither did I intend to disparage seismological investigations on the plain of Yedo, but it does seem to me that the first thorough study, such as Prof. Ewing and others have initiated, should be in a locality where the minimum of disturbing influences would be able to complicate the results. In fact, we should expect much more progress in arithmetic in a child which commences by learning to count than in another that is immediately put to study fractions. I should never suggest that one earth-shaken locality should be continuously studied more than another when once we have decided upon the most serviceable and accurate registering apparatus.

Now as a resident in a country continuously shaken by earthquakes, many of which are disastrous, and where investigators are few and far between, we want instruments that give the least complicated tracings possible if we are to find observers amongst inhabitants of the Italian provincial towns. The same thing holds good to a variable extent in other countries.

Again, hardly any one would accuse me of claiming entire originality for the principle in the apparatus described. For example, every one knows that the pendulum has been used as a seismograph for centuries even. All that I claim is a combination of different forms of actuating and registering apparatus, with a few novel introductions, for it is practically impossible to invent, in the true sense of the word, a new seismograph any more than a new locomotive.

Perhaps, in my critic's opinion, we have reached perfection in seismographic instruments, which it appears is not shared by many workers, as the continual new suggestions and modifications indicate, as does also the fact that throughout all the observingstations so far instituted it is rare to find two provided with similar instruments.

In regard to Prof. Ewing's last paragraph, perhaps experience will determine whether my suggestions do really lie outside the sphere of practical seismology.

In conclusion I shall be happy to hear suggestions for any improvements from others, for in my own humble opinion we do not yet possess a single seismograph that reaches near to perfec- 